ISSN: 2526-7884

Editor: Prof. Dr. Marconi Freitas da Costa Email da revista: cbr@ufpe.br
Avaliação: Double blind review

Recebido: 20 de agosto de 2019

Aceito: 21 de setembro de 2019

\title{
MÍDIAS DIGITAIS E REAÇÕES NEGATIVAS ÀS CAMPANHAS PUBLICITÁRIAS LGBT
}

\author{
Arize Sousa Fernandes Oliveira \\ Monica Machado
}

\begin{abstract}
Arize Sousa Fernandes Oliveira é Mestranda do Programa de Pós-graduação em Psicossociologia de Comunidades e Ecologia Social - Eicos, do Instituto de Psicologia da Universidade Federal do Rio de Janeiro IP/UFRJ.

E-mail: arizefernandes@gmail.com

Monica Machado é Professora Associada da Escola de Comunicação da Universidade Federal do Rio de Janeiro - UFRJ.

E-mail: monica.machado@eco.ufrj.br

Os autores agracedecem aos avaliadores pelos comentários para melhoria do artigo.
\end{abstract}

\begin{abstract}
Resumo
"Por que não investem em outra causa? Essa é safadeza pura", "Heteros, vamos boicotar" e "É só pra vender mais" foram alguns dos comentários observados nas campanhas publicitárias online analisadas nesta pesquisa. O digital é uma experiência sociocultural, revelador de vínculos entre vivências locais e os usos das mídias digitais. Assim, ao analisar conteúdos que circulam na internet é possível construir um panorama dos contextos em que estão inseridos. Foram investigados os comentários no Facebook das campanhas \#AvonPride, \#MarcasAliadas e \#OAmorNosConecta, promovidas, respectivamente, pela Avon, Skol e Uber, empresas signatárias do Fórum Empresas e Direitos LGBT. Os resultados da pesquisa apontaram opiniões que expressam desvalorização ao apoio, declarações de abandono de consumo e acusação de oportunismo. Ainda assim, vale destacar que a expressiva maioria dos comentários nas ações é positiva e muitas pessoas se identificam com os conteúdos: as mídias digitais podem gerar oportunidades para novas perspectivas sociais.

Palavras-chave: Antropologia digital, Comunidades, LGBT, Mídias sociais.
\end{abstract}




\section{INTRODUÇÃO}

Mesmo que aparentemente estejamos vivendo "uma sociedade mais aberta, mais tolerante e mais sensual" (Spargo, 2017, p.10), a intolerância contra sexualidades não normativas ainda se faz presente. Em 2017, o número de assassinatos de LGBTsi chegou a 445 mortes, o que torna o Brasil campeão mundial de crimes contra LGBTs, superando inclusive países onde há pena de morte contra homossexuais (GGB, 2018). Nesse contexto, o presente estudo se concentrou em investigar reações online contrárias às campanhas publicitárias que apoiam causas LGBT, através da análise de comentários nas mídias sociais que ilustram o descontentamento com as ações.

A fim de direcionar o olhar para empresas com propósitos de contribuição LGBT mais consolidados, a seleção das campanhas foi realizada com base na divulgação realizada pelo Fórum Empresas e Direitos LGBT, que exibe em seu site a atividade das signatáriasii. Lá foram identificadas três campanhas que envolviam mídias sociais, promovidas pela Avon, Skol e Uber. Assim, suas respectivas campanhas \#AvonPride, \#MarcasAliadas e \#OAmorNosConecta tiveram seus comentários no Facebook analisados.

Os critérios para a avaliação das reações contrárias foram baseados no método de análise de conteúdo (Bardin, 1977). Os resultados da pesquisa foram agrupados, e dos comentários negativos, $21 \%$ abordam desvalorização do apoio a outras causas que seriam mais importantes; 9\% declaram abandono de consumo das marcas e $6 \%$ acusam as empresas de oportunistas. Os outros 64\% dos comentários argumentam críticas mais genéricas, debochando da ação ou atacando LGBTs.

\section{FUNDAMENTAÇÃO}

As marcas de produtos, com certa frequência, têm buscado usar em seus discursos o apoio a causas sociais, o incentivo a demandas coletivas e, por vezes, prestam assistência a grupos que sofrem com preconceito na sociedade. Aqui, neste trabalho, as marcas avaliadas abraçaram a causa LGBT. Antes da seção destinada à análise dos discursos midiáticos e o estudo de recepção das campanhas, estão pontuadas nesta seção de
'Fundamentação' algumas referências teóricas que tratam desse fenômeno na publicidade e também as que abordam as relações nas mídias digitais em seu aspecto mais sociocultural.

\section{Consumo e politização}

Diversos autores tratam da relação entre consumo e politização, dos aspectos mais ativistas da publicidade e do incentivo das marcas ao engajamento do consumidor com causas sociais.

Essas ideias partem da consideração do consumo como lugar privilegiado para entender nossa sociedade. A vida social é constituída de uma cultura do consumo (Slater, 2002) e, nesse universo, os bens funcionam como comunicadores de sentido (Douglas \& Isherwood, 2004). 0 discurso publicitário, neste âmbito, constrói e comunica às pessoas o significado simbólico dos produtos e serviços, e faz parte da vivência coletiva (Machado et al, 2014). Como está sintetizado no trecho a seguir:

O consumo é coletivamente compartilhado de modo que as pessoas, além de receberem ou incorporarem os significados veiculados pelo discurso publicitário, nas interações sociais também constroem e atribuem, elas mesmas, significados aos bens. [...] As pessoas se envolvem umas com as outras também a partir dos laços criados nas práticas de consumo, nas trocas simbólicas que são aí estabelecidas e que podem ser estimuladas e mediadas pelo discurso publicitário. (Machado et al., 2014, n.p).

Canclini (1995) afirma que através da seleção e apropriação dos bens materiais, definimos aquilo que consideramos publicamente valioso. Assim, as práticas consumistas teriam a capacidade de delinear um "novo senso de cidadania, mais associado ao consumo privado de bens e à mídia" (Machado, 2011, n.p). Ou seja, há uma orientação de consumo que ultrapassa a utilidades dos bens: o consumidor é afetado pela dimensão simbólica das mercadorias (Miranda, 2017). Nesse sentido, as mensagens publicitárias se destinariam a um consumidor-cidadão, que pode fazer de sua compra uma ferramenta de transformação da sociedade (Akatu, 2002).

No livro 'Consumo e politização: discursos publicitários e novos engajamentos juvenis', a pesquisadora Mônica Machado aponta que os 
jovens de hoje se envolvem com micronarrativas, com ativismo marcado por temas de luta contra o preconceito social. A autora também afirma que a ocupação do espaço público é redesenhada e muitas vezes sustentada no espaço virtual. Ela observa que o ciberativismo aponta como uma nova tendência, o que pode ser evidenciado com os diversos coletivos e movimentos online que surgem e são mantidos no espaço digital. No âmbito das causas LGBT, podem ser mencionados diversos movimentos online, desde o uso de hashtags que simbolizam os conteúdos (como \#OrgulhoLGBT, \#AmorÉAmor, \#OAmorVence e \#ParadaDoOrgulho) até plataformas mais elaboradas que disponibilizam mapas interativos que documentam momentos do público gay (como o Places of Pride e o NYC LGBT Historic Sites Project).

Ou seja, através dos bens de consumo e da mídia, as pessoas são ativas politicamente e adotam causas sociais. As marcas, por sua vez, apostam em discursos de engajamento e cidadania. Como será detalhado na seção de 'Análise das campanhas' deste trabalho, Avon, Skol e Uber apostaram na dimensão simbólica do consumo ao adotarem em suas campanhas o discurso publicitário que abraça a causa LGBT.

\section{A internet e os vínculos socioculturais}

A perspectiva que se adotada neste trabalho é a da antropologia digital, que compreende o digital como uma experiência sociocultural, revelador de vínculos entre vivências locais e os usos das mídias digitais. 0 que se acredita é que aquilo que existe online é resultado do que se desenrola na arena offline, com espaço para elaboração de novas ideias que têm impacto na vida cotidiana.

Horst \& Miller (2012) exploram a importância de uma abordagem antropológica da cultura digital. De acordo com eles, a ascensão do digital trouxe um novo ímpeto para a antropologia, que seria uma das poucas disciplinas capazes de entender como a cultura digital torna-se cultura normativa. As principais afirmações deles podem ser sintetizadas em três pontos: (1) a tecnologia digital não transformou fundamentalmente o que significa ser humano, (2) a cultura digital não é mais mediada do que antes e (3) a humanidade dentro do contexto digital não é menos autêntica que a vida pré-digital. Como pode ser visto no trecho a seguir:

Explicando de forma mais genérica, o surgimento da antropologia digital como um subcampo, está em oposição resoluta a todas as abordagens que sugerem que se tornar digital nos tornou menos humanos, menos autênticos ou mais mediados. Não somente permanecemos tão humanos quanto antes dentro do mundo digital, como o digital também oferece muitas novas oportunidades para a antropologia nos ajudar a entender o que significa ser humano (Horst \& Miller, p.4, 2012, tradução livre).

Miller et al (2016), ao tratar especificamente das sexualidades não normativas descreve que as plataformas digitais podem dar oportunidades para que pessoas LGBT expandam suas atividades para interações privadas/secretas ou também para obter mais visibilidade pública. Os autores comparam pesquisas nas mídias sociais realizadas em diversos lugares do mundo, e em alguns casos, as mídias sociais podem ser hiperconservadoras, restritivas e até vigiadas pelo governo. As mídias sociais reproduzem e reforçam normas que regulam as diferenças de gênero e sexualidade no mundo off-line, mas de maneiras diferentes e em diferentes graus (Miller et al, 2016).

Nesse sentido, uma contribuição importante para este trabalho, ancorada na antropologia digital, é a ideia de socialidade escalável. Os autores explicam que é essa ideia de socialidade escalável que nos permite entender como as mídias sociais podem ser simultaneamente mais conservadoras e mais liberais do que a vida offline:

Da manutenção de relações íntimas às possibilidades de formar relacionamentos com estranhos, as mídias digitais podem ser vistas como uma forma de "socialidade escalável", permitindo que as pessoas controlem melhor suas vidas sociais. Isso pode ser através da adaptação de normas sociais existentes a diferentes contextos ou permitindo a criação de formas inteiramente novas de relações sociais e socialidade, explorando esse registro de graus de intimidade e distância. (Miller et al, 2016, p. 3 , tradução livre). 
$\mathrm{Ou}$ seja, existem muitas dimensões diferentes de como os relacionamentos online são classificados, assumindo maior distância ou proximidade de acordo com um contexto social variável. As mídias sociais online reforçam, interrompem ou simplesmente transferem sistemas de sexualidade dos contextos locais, por isso que a internet e as tecnologias digitais, em geral, não são inerentemente transformadoras ou conservadoras. Em vez disso, elas existem apenas através de uma prática social variável.

Uma outra consideração importante trazida por Miller et al (2016) dialoga com o que Rubin (2003) afirma sobre a existência de uma hierarquia de comportamentos sexuais. De acordo com o que os autores defendem, as atitudes mais próximas de um padrão familiar e com identificação normativa de gênero são mais aceitas nas mídias digitais:

Gays e lésbicas parecem ter sua presença na mídia social aceita desde que atuem de maneira normativa quanto ao gênero, por exemplo - permanecendo intimamente associados com suas famílias natais e assumindo trabalho considerado apropriado para seu gênero; em tais casos, eles relatam ter pouca discriminação. No entanto, aqueles que agem fora das normas de gênero sentem desaprovação. Como resultado, indivíduos como homens que atuam no arrasto criam perfis falsos de mídia social para esses fins. (Miller et al, 2016, p.125, tradução livre).

Como será visto na seção de 'Análise das campanhas' essa hierarquia e o privilégio à identificação normativa de gênero podem ser observados nas reações do público.

\section{METODOLOGIA}

A metodologia usada para analisar as campanhas das três marcas foi a análise de conteúdo, conforme a conceituação proposta por Bardin (1977). Assim como afirma a pesquisadora, a análise de conteúdo não é um instrumento único e rígido com regras fixas e etapas bem circunscritas. Trata-se de um procedimento que vai se construindo ao se realizar, seguindo algumas direções básicas (Bardin, 1977).

Sobre essas direções básicas, cabe dizer que neste trabalho foi utilizado o modelo descrito por Bardin (1977), composto por três etapas: pré-análise, exploração do material e tratamento dos resultados e interpretações.

$\mathrm{Na}$ fase da pré-análise, foram escolhidas as campanhas de apoio LGBT a serem avaliadas. A fim de direcionar o olhar para empresas com propósitos de contribuição LGBT mais consolidados, a seleção das campanhas foi realizada com base na divulgação realizada pelo Fórum Empresas e Direitos LGBT. O Fórum reúne desde 2013 companhias que discutem estratégias, desafios e principais práticas para gestão da diversidade no segmento LGBT (Sales, 2017).

As signatárias assumiram compromissos no âmbito interno e práticas para contribuir com o tema na sociedade. Com encontros constantes para a comunidade empresarial, LGBTI+, governos, órgãos da $\mathrm{ONU}$, entre várias outras, o Fórum fomenta o diálogo e a cooperação entre as empresas para que consigam chegar ao cumprimento dos compromissos propostos. Esses compromissos envolvem a promoção de oportunidades igualitárias de trabalho, campanhas e serviços respeitosos e também apoio ao desenvolvimento dos direitos LGBT na comunidade.

Como a dimensão digital era um pressuposto fundamental para análise, foram privilegiadas as três campanhas que envolviam mídias sociais, identificadas no site do Fórum, promovidas pela Avon, Skol e Uber. Assim, suas respectivas campanhas \#AvonPride, \#MarcasAliadas e \#OAmorNosConecta tiveram seus comentários no Facebook analisados. 0 foco na análise dos comentários buscou observar, nessa recepção do discurso publicitário, o sentido negativo atribuído pelos interlocutores. A hipótese inicial era de que as campanhas seriam recebidas com muitos comentários de desaprovação, já que mesmo que a visibilidade homossexual avance no Brasil, sempre existirá uma reação conservadora (Trevisan, 2018).

Bardin (1977) também indica a formulação de indicadores e categorização para análise do conteúdo. 0 indicador utilizado aqui foi a frequência de comentários ou reações no Facebook que explicitavam desaprovação da campanha. Cabe registrar que o volume de comentários positivos nas campanhas é significativamente maior. Aqui, vale mencionar que a existência do algoritmo no Facebookiii é uma das razões para que os posts das marcas 
tenham recebido um volume muito maior de comentários positivos do que negativos, afinal eles aparecem com mais visibilidade de acordo com o interesse dos usuários. Ainda assim, reações e comentários negativos foram contabilizados e é sobre eles que lançamos o olhar neste trabalho.

As reações negativas foram contabilizadas de acordo com a classificação do Facebook, que desde 2016 permite que os usuários da rede social possam ter outras reações para as publicações além do "Curtir", como "Amar" ou gargalhar. Como reação negativa para a avaliação das campanhas foram consideradas as reações de "Grr", que sinaliza raiva e é representado por um emoji com cabeça quente, e "Triste", que é representado por um emoji chorando.

Todas as campanhas receberam centenas de comentários. Foram analisados aqui os que revelavam desaprovação, pela causa em si ou pelo discurso da marca. A categorização dos comentários foi realizada de acordo com o volume de declarações que se enquadravam em um mesmo tema, assim, os comentários foram agrupados nas categorias "Aborda desvalorização do apoio a causas mais importantes"; "Identifica oportunismo"; "Declara abandono da marca" e "Indica crítica genérica”, mais bem explicados a seguir:

\section{Aborda desvalorização do apoio a causas mais importantes:}

Nesta categoria foram agrupados os comentários que não consideravam o apoio à causa LGBT legítima por existirem outras que seriam mais importantes. "Por que não investe em outra causa? Essa é Safadeza pura" e "E sobre a família? Estão com algum projeto?" são exemplos dos comentários encontrados nesse sentido. A desqualificação do movimento é uma das evidências do preconceito.

\section{Identifica oportunismo}

Aqui, foram concentrados os comentários que explicitam a apropriação da imagem e do discurso de determinados grupos pelas marcas, a fim de estabelecer um vínculo e atraí-los como consumidores. Neste caso, para além da questão da intolerância com a homossexualidade, as pessoas condenam o discurso publicitário por considerarem apelativo.

\section{Declara abandono da marca}

Nesta categoria estão os comentários que revelam total insatisfação com o discurso publicitário. Aqui, as pessoas se mostram ofendidas com a iniciativa LGBT ao ponto de deixarem de consumir os produtos das marcas que dão apoio à causa.

\section{Indica crítica genérica}

Muitos comentários atingiam pontos diversos de intolerância: ofensas diretas, defesa dos valores da família heteronormativa, apoio ao "macho homem" e outros. Esses todos foram agrupados nesta categoria.

Segue na seção a seguir a descrição das fases de exploração do material e a intepretação dos resultados.

\section{ANÁLISE DAS CAMPANHAS}

Nessa seção segue detalhada a análise da recepção das três campanhas e seus diferentes graus de recusa dos discursos. Como todas as marcas avaliadas participam do Fórum Empresas e Direitos LGBT, conforme foi explicado na 'Metodologia', elas já possuem o tema evidenciado em sua estrutura discursiva institucional. Assim, também será brevemente apresentado como a marca atua neste contexto.

\section{Avon e \#AvonPride}

A empresa norte-americana de cosméticos lançou em junho deste ano uma campanha para celebrar a Semana de Orgulho LGBTQIA+ e estimular a reflexão sobre o tipo de visibilidade que a comunidade atrai. Defendendo "a beleza de ser quem você é, para ser vista e respeitada em toda parte, em todas as pessoas" (Avon, 2018, n.p), a campanha questionou o que atrai tantos olhares para as mãos dadas, jeitos e roupas das pessoas LGBTQIA+ e criou um manifesto reunindo pessoas que chamam a atenção por onde passam. "Da mesma maneira que essas pessoas, a comunidade LGBTQIA+ é impossível de ser ignorada" (Avon, 2018, n.p). A campanha tem uma seção especial no site da marcaiv, que reúne todos os detalhes da ação. 


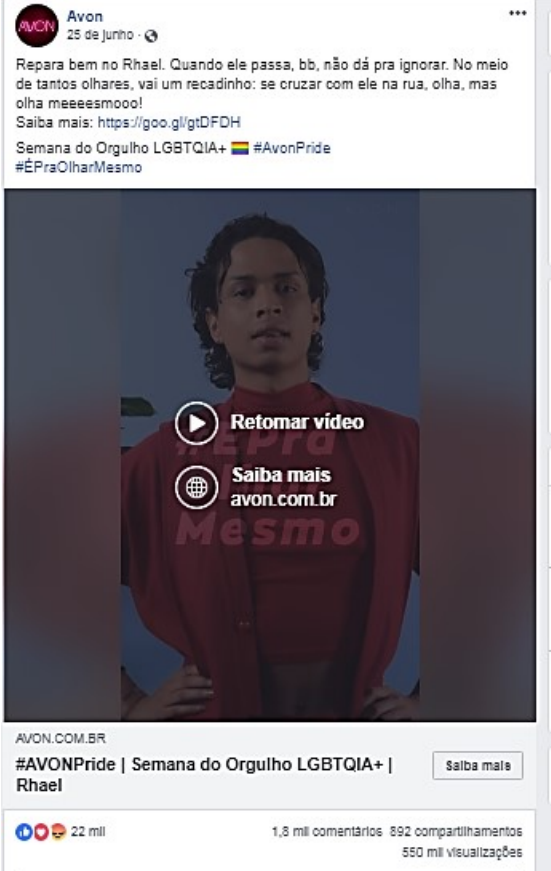

Fonte: Perfil oficial da Avon no Facebook

Figura 1: Post \#AvonPride no Facebook página da Avon no Facebook, foram postados os seis vídeos com trechos de depoimentos de pessoas da comunidade LGBTQIA+. Cada protagonista explica por que é notado e entre as razões estão suas habilidades, talentos, personalidades e conquistas. 0 post que teve seus comentários avaliados neste trabalho foi o do primeiro vídeo, que recebeu o maior volume de interações na rede social (Figura 1). 0 depoimento é de Rhael Lima de Oliveira, mais conhecido como Lia Clark, cantora e artista brasileira.

A publicação recebeu 1.800 comentários, desses, 133 expressavam desaprovação. E dentre as 22.000 reações, 1.000 eram negativas. Nos comentários, a maioria fazia uma crítica genérica, com ofensas ao público LGBT e defesa de valores heteronormativos. 0 quadro a seguir explicita a quantidade encontrada de acordo com a categorização e mostra alguns exemplos de comentários:

\begin{tabular}{|c|c|c|}
\hline Categoria & QTD & Exemplos \\
\hline $\begin{array}{l}\text { Aborda desvalorização do } \\
\text { apoio a causas mais } \\
\text { importantes }\end{array}$ & 2 & "E sobre a família? Estão com algum projeto?"; "E o desemprego?". \\
\hline Identifica oportunismo & 5 & $\begin{array}{l}\text { "Avon ganhando dinheiro" ; "É uma estratégia de marketing } \\
\text { apelativa" ; "Puro ibope"; "a Avon se aproveita disso para se } \\
\text { promover e ganhar likes e comentários.. Eh tudo interesse!!". }\end{array}$ \\
\hline Indica crítica genérica & 123 & $\begin{array}{l}\text { "Meu Deus, é o fim dos tempos"; "Aqui vemos um post sobre } \\
\text { respeito onde os heterossexuais são desrespeitados"; "Direitos } \\
\text { iguais? Cadê a parada hétero? Nunca vi"; "Me poupe"; "Fim dos } \\
\text { tempos!!!! apocalipse se cumprindo ponto a ponto"; "E por isso que } \\
\text { está falindo"; "Era só o que me faltava"; "O mundo simplesmente } \\
\text { se perdeu"; "Reprovadíssimo"; "Sem comentários, mas acho que é } \\
\text { o fim do mundo"; "Veado dos inferno, tem que eliminar tudo esses } \\
\text { tipo de lixo". }\end{array}$ \\
\hline Declara abandono da & 3 & $\begin{array}{l}\text { "Não compro mais Avon"; "Adeus, marca. Nunca mais"; "Perderam } \\
\text { um cliente"; "Estou dando uma ajuda daquelas, descurtindo a } \\
\text { página". }\end{array}$ \\
\hline
\end{tabular}

Fonte: Elaborado pelos autores.

Quadro 1: comentários no post da campanha da Avon \#AvonPride

\section{Skol e \#MarcasAliadas}

Desde 2015, a Skol, uma das marcas de cerveja do grupo Ambev, se reposicionou no mercado, deixando alguns estereótipos machistas de lado e abraçando uma comunicação mais inclusiva (MEIO\&MENSAGEM, 2018). Patrocinadora da Parada do Orgulho LGBT em São Paulo há três anos, a marca defende a causa através de diversas iniciativas. Em maio deste ano, a Skol lançou a campanha \#MarcasAliadas, convidando outras marcas, que também acreditam na construção de uma sociedade que valoriza o respeito, a doarem parte de seus nomes para a causa. Juntas elas formaram a sigla LGBTQ+: a Skol com o "L", Burger King 
com o "G", Bis com o "B", Trident com o "T" e quem disse, berenice?, com o " $Q$ ". Todas as marcas aliadas fizeram doações financeiras a quatro instituições que lutam pelos direitos LGBTQ+. A campanha tem um site específicov que explica a iniciativa, apresenta as instituições que irão receber o auxílio financeiro e também todas as marcas que apoiaram a campanha, com suas devidas letras L, G, B, T ou $\mathrm{Q}$ destacadas.

\begin{tabular}{|c|c|c|}
\hline Categoria & QTD & Exemplos \\
\hline $\begin{array}{l}\text { Aborda desvalorização do apoio a } \\
\text { causas mais importantes }\end{array}$ & 59 & $\begin{array}{l}\text { "Animais, orfanatos, hospitais merecem mais } \\
\text { atenção"; "Essa causa é um desperdício de dinheiro" } \\
\text {; "Por que não investe em outra causa? Essa é } \\
\text { Safadeza pura". }\end{array}$ \\
\hline Identifica oportunismo & 12 & $\begin{array}{l}\text { "Nova estratégia de marketing"; "Só pra vender } \\
\text { mais". }\end{array}$ \\
\hline Indica crítica genérica & 40 & $\begin{array}{l}\text { "Ridículo"; "Ninguém se importa"; "Falta de } \\
\text { vergonha"; "No mínimo esses diretores estão } \\
\text { queimando a rosca"; "Palhaçada"; "Tanta viadagem } \\
\text { que daqui a pouco o macho homem irá entrar em } \\
\text { extinção". }\end{array}$ \\
\hline Declara abandono da marca & 23 & $\begin{array}{l}\text { "Perdeu o meu respeito e não consumo mais } \\
\text { nenhuma delas, algumas nem gosto outras } \\
\text { substituirei"; "Por essas e outras prefiro } \\
\text { [concorrentes]. Parece sermão da patrulha do } \\
\text { politicamente correto"; "Agora pra mim é só } \\
\text { Itaipava ou Skin"; "\#partiumudardemarca"; "Vou } \\
\text { tomar outra cerveja que não esteja ligada a Ambev"; } \\
\text { "Não tomo mais nem que seja de graça" "Fui, parei } \\
\text { de tomar"; "Partindo pra outra marca em 3, 2, 1"; } \\
\text { "Vamos boicotar, heteros não bebam" }\end{array}$ \\
\hline
\end{tabular}

Fontes: Elaborado pelos autores

Quadro 2: Comentários no post da campanha da Skol \#MarcasAliadas

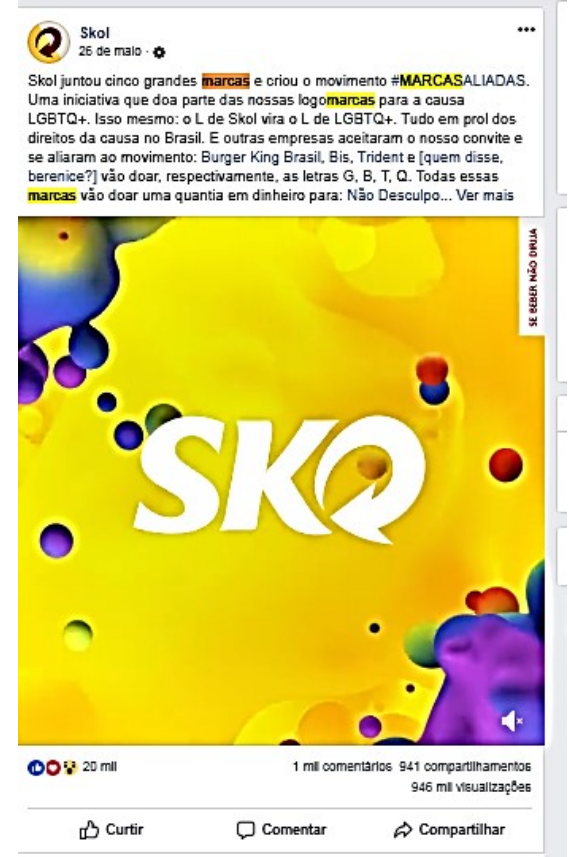

Fonte: Perfil oficial da Skol no Facebook

Figura 2: Post \#MarcasAliadas no Facebook
A publicação no Facebook que anunciava a iniciativa (Figura 2) recebeu 1.000 comentários e mais de 20.000 reações. Foram contabilizados 134 comentários de desaprovação e 148 reações não positivas. A categorização e os exemplos seguem no quadro 2 .

\section{Uber e \#OAmorNosConecta}

A Uber, prestadora de serviços de transporte privado, defende um ambiente seguro e inclusivo para o público LGBTI nas viagens feitas pela plataforma Uber. Ela apoia a causa de diversas maneiras e sua página no Facebook é a que mais contém conteúdo de apoio para o público LGBT, dentre as marcas analisadas para este trabalho. No ano passado, a empresa lançou o vídeo/documentário \#OAmorNosConecta, afirmando seu compromisso com a comunidade LGBTI+.

O vídeo no Facebook, que dura aproximadamente 14 minutos, recebeu cerca de 
300 comentários, sendo 21 negativos, e das 1.000 reações, 50 desaprovavam a ação, como pode ser observado no quadro 3 (não foram identificados comentários que declaram desvalorização de causas que seriam mais importantes, nem de abandono de marca, por isso essas linhas foram supridas do quadro).

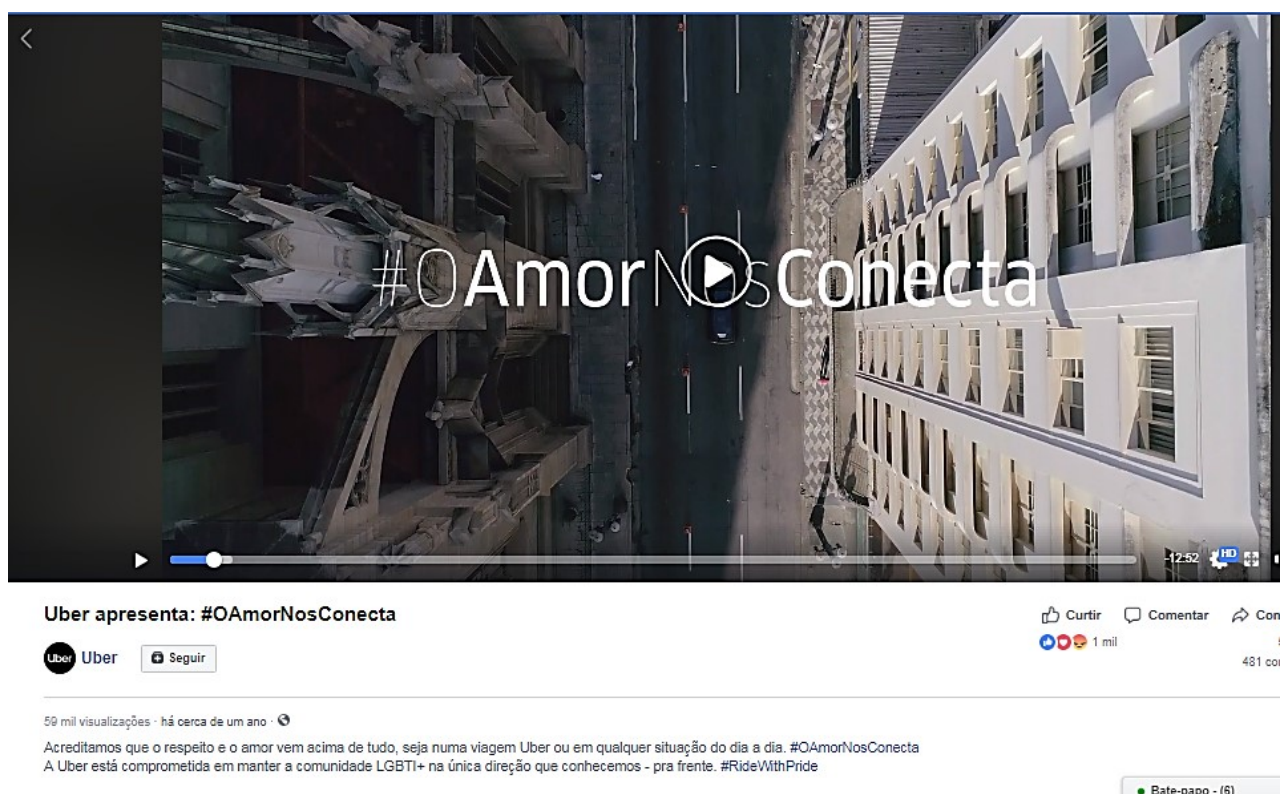

Fonte: Perfil oficial da Uber no Facebook

Figura 3: Post do vídeo \#OAmorNosConecta no Facebook

Assim, de forma resumida, do total de comentários negativos, $21 \%$ abordam desvalorização do apoio a outras causas que seriam mais importantes; 9\% declaram abandono de consumo das marcas e $6 \%$ acusam as empresas de oportunistas. Os outros 64\% dos comentários argumentam críticas mais genéricas, debochando da ação ou atacando LGBTs.

\begin{tabular}{|c|c|c|}
\hline Categoria & QTD & Exemplos \\
\hline $\begin{array}{l}\text { Identifica } \\
\text { oportunismo }\end{array}$ & 1 & "Apoiam nada, só querem nossa grana" \\
\hline $\begin{array}{l}\text { Indica crítica } \\
\text { genérica }\end{array}$ & 20 & $\begin{array}{l}\text { "Dane-se, ninguém liga. Até a Uber com essa militância agora? pqp. Ridículo"; } \\
\text { "A "Parada" é financiada com dinheiro público e vocês apoiam isso? --' mas } \\
\text { que poha hein?"; "Uber vocês estão apostando em transportar somente a } \\
\text { comunidade gay? Me parece um tiro no pé do UBER"; "Falta de vergonha, } \\
\text { além de ser uma empresa clandestina agora apoia uma coisa dessa, o mundo } \\
\text { está mesmo perdido"; "Que palhaçada agora é essa?"; "Que horror, fora } \\
\text { LGBT". }\end{array}$ \\
\hline
\end{tabular}

\section{Sobre os resultados}

Trevisan (2018) afirma que o consumismo do chamado pink moneyvi não apaga as marcas de intolerância contra LGBTs. Mesmo com a condescendência que aceita a homossexualidade, a reprovação ainda se faz presente, como pôde ser observado com os comentários analisados neste trabalho. A ala conservadora "permanece de prontidão, sempre alerta para vigiar" (Trevisan, 2018, p. 23), e pelo o que se pode interpretar do material coletado, a intolerância se apresenta de diversas formas. 
Os comentários que contestam o apoio denotam a inferiorizarão social. Quando lemos "Animais, orfanatos, hospitais merecem mais atenção"; "Essa causa é um desperdício de dinheiro"; "Por que não investe em outra causa? Essa é Safadeza pura" fica evidente que essas pessoas consideram inaceitável qualquer política de igualdade que beneficie a comunidade LGBT.

A solidariedade é tão remota e a identificação tão impensável, que muitos, além de não expressarem apoio, declaram abandonar a marca, como fica claro quando afirmam "Perderam meu respeito, não consumo mais", "Perderam um cliente" ou "\#partiumudardemarca". A hostilidade também pode ser vista em comentários como "Tem que eliminar esses tipos de lixo". 0 preconceito, que exclui e inferioriza aqueles que são classificados como homossexuais (Prado \& Machado, 2008) aparece em muitas declarações, curtas ou longas, mais ou menos agressivas, como "Palhaçada", "Me poupem"; "Sem comentários, mas acho que é o fim do mundo".

Nesses comentários e reações ficam também ficam explícitas algumas das formas de homofobia descritas por Borrillo (2001). Uma delas é a mais violenta, caracterizada por um sentimento de medo, aversão e repulsa, como é o caso de "Que horror, fora LGBT". Outra forma de homofobia tem manifestações em defesa da heterossexualidade e do machismo. Como explicado no trecho a seguir:

\begin{abstract}
Nas sociedades marcadas pela dominação masculina, a homofobia organiza uma espécie de "vigilância do gênero", denunciando desvios do masculino em direção ao feminino e vice-versa, se opera uma atualização constante nos indivíduos, lembrando-os do seu "gênero certo" (Borillo, 2001)
\end{abstract}

Isso pode ser observado nos comentários: "Aqui vemos um post sobre respeito onde os heterossexuais são desrespeitados" e "Tanta viadagem que daqui a pouco o macho homem irá entrar em extinção". Alguns não entendem a direção do preconceito e sugerem mobilizações pela heterossexualidade: "Direitos iguais? Cadê a parada hétero? Nunca vi", outros chegam a convocar ações coletivas: "Vamos boicotar, heteros não bebam".
Enfim, são muitas as interpretações que podem ser feitas a partir dos comentários e aqui foram pontuadas apenas algumas das possíveis. Assim como foi imaginado na hipótese, foram encontrados muitos comentários negativos. Mas, ainda que eles existam, muitos foram os comentários de apoio e solidariedade, que mostram que a comunidade tem sido recebida com mais tolerância, pelo menos nos comentários dessa campanha.

\section{CONSIDERAÇÕES FINAIS}

Este trabalho faz parte de uma investigação maior sobre redes de apoio LGBT e suas articulações online, pesquisa de mestrado, ainda em fase de aprofundamento.

Dentro da pluralidade do fenômeno do consumo político, o objeto aqui estudado levou em consideração a reação homofóbica ao apoio de marcas a causas LGBT. Avon, Skol e Uber expressaram o apoio à diversidade sexual nos discursos de suas campanhas. Ao avaliar as mensagens postadas por aqueles que demonstraram insatisfação com o conteúdo das publicações, buscamos mapear o que as pessoas alegavam ao reprovar as iniciativas de apoio. Foi encontrado como resultado dessa avaliação comentários que declaram a existência de outras causas que seriam mais importantes, afirmam o abandono de consumo, acusam o oportunismo das marcas e muitos fazem críticas mais genéricas, debochando da ação ou atacando LGBTs.

Ainda assim, vale destacar que a expressiva maioria dos comentários nas ações é positiva e muitas pessoas se identificam com os conteúdos, acompanhando aquilo que Miller et al (2016) afirmam: as mídias digitais geram oportunidades de criar perspectivas sociais, inclusive no campo das sexualidades. Podem fomentar espaços de informação, aproximação e resistência, diante da intolerância expressa.

\section{REFERÊNCIAS}

Akatu. (2002). Consumidor, o poder da consciência. São Paulo: Instituto Akatu.

Avon. (2018). Avon Pride. Disponível em https://www.avon.com.br/avon-pride, recuperado em 3, novembro, 2018. 
Bardin, L. (1977). Análise de conteúdo. Lisboa: Edições 70.

Borrillo, D. (2001). Homofobia. Barcelona: Edicions Bellaterra.

Cavalcante, R. B. et al. (2014). Análise de Conteúdo: considerações gerais, relações com a pergunta de pesquisa, possibilidades e limitações do método. Informação \& Sociedade: Estudos, 24(1), 13-18.

Douglas, M.\& Isherwood, B. (2004). O mundo dos bens: para uma antropologia do consumo. Rio de Janeiro: UFRJ.

GGB. (2017). Pessoas LGBT mortas no Brasil: relatório 2017. Disponível em: https://homofobiamata.files.wordpress.com/ 2017/12/relatorio-2081.pdf, recuperado em 3 , novembro, 2018.

Machado, M. (2011). Consumo e politização: discursos publicitários e novos engajamentos juvenis. Rio de Janeiro, Mauad.

Machado, M. et al. (2011). Publicidade para causas sociais: apontamentos sobre a experiência do laboratório universitário de publicidade aplicada (LUPA). Revista Signos do Consumo, $3(1)$.

MEIO\&MENSAGEM. (2017). Skol assume passado machista e ressalta a importância de evoluir. Disponível

em: http://www.meioemensagem.com.br/home/c omunicacao/2017/03/09/skol-assumepassado-machista-e-ressalta-a-importanciade-evoluir.html, recuperado em 3 , novembro, 2018.

Miller, D. et al. (2016). How the world changed social media. UCL press.

Miranda, A. P. (2017). Consumo de moda: a relação pessoa-objeto. 2 $2^{\mathrm{a}}$ Edição. São Paulo: Estação das Cores e Letras.

Prado, M. \& Machado, V. (2018). Preconceito contra homossexualidades: a hierarquia $d a$ invisibilidade. São Paulo: Editora Cortez.

Sales, G. (2015). Diversidade no Trabalho: valores organizacionais e adesão a normas em organizações participantes do Fórum Empresas e Direitos LGBT. Anais do $V$ Congresso Internacional Comunicação $e$ Consumo: São Paulo.

Slater, D. (2002). Cultura do consumo \& modernidade. São Paulo: Nobel.

Spargo, T. (2017). Foucault e a teoria queer: seguido de Ágape e êxtase: orientações pós-seculares. Belo Horizonte: Autêntica Editora.

Trevisan, J. (2018). Devassos no Paraíso: a homossexualidade no Brasil, da colônia à atualidade. Rio de Janeiro: Objetiva.

\title{
Digital Media and Negative Reactions to LGBT Advertising
}

\begin{abstract}
"Why not invest in another cause?" is one the comments observed in the online advertising campaigns analyzed in this research. Digital is a socio-cultural experience, revealing the links between local experiences and the uses of digital media. Thus, by analyzing content circulating on the internet, it is possible to create an overview of the contexts in which they are inserted. Comments were searched on Facebook for the campaigns \#AvonPride, \#MarcasAliadas and \#OAmorNosConecta, promoted respectively by Avon, Skol and Uber, signatories of the Forum Companies and LGBT Rights. The survey results pointed to opinions expressing devaluation of support, abandonment requirements and accusation of opportunity. Still, it is noteworthy that most comments expressed in actions are positive and many people identify with content: digital media can generate opportunities for new social perspectives.

Keywords: digital anthropology; communities; LGBT; social media.

\footnotetext{
' Optamos por usar a sigla LGBT (lésbicas, gays, bissexuais e transexuais) por ela ser comumente utilizada, nos dias de hoje, para se referir a orientações sexuais diferentes da heterossexual e/ou de orientações de gênero diferentes da cisgênera.

ii Disponível em: http://www.forumempresaslgbt.com/artigos/atividades-das-signatarias/

iii $\mathrm{O}$ algoritmo do Facebook é um recurso utilizado para, principalmente, determinar o que é posto em primeiro no seu feed da tela principal. Para entender o que realmente interessa ao usuário, a rede utiliza uma série de fatores individuais, que determinam a busca de combinações, definindo o que deve, ou não, vir a figurar na tela inicial. Desta forma, podemos supor que as campanhas tenham tido maior visualização pelos apoiadores da causa LGBT.

${ }^{\text {iv }}$ Disponível em: https://www.avon.com.br/avon-pride, recuperado em 31, agosto, 2019.

${ }^{\vee}$ Disponível em: http://www.marcasaliadas.com.br/, recuperado em 31, agosto, 2019.

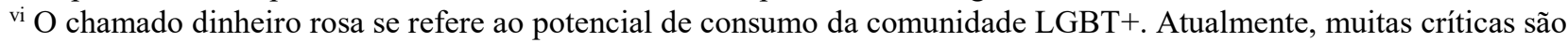
feitas a empresas que enxergam com nessa abordagem, uma oportunidade meramente mercadológica.
} 